\title{
ADVANCED SUPERSOLVUS NICKEL POWDER DISK ALLOY DOE: CHEMISTRY, PROPERTIES, PHASE FORMATIONS AND THERMAL STABILITY
}

\author{
Andrew Powell ${ }^{1}$, Ken Bain ${ }^{1}$, Andrew Wessman ${ }^{1}$, Daniel Wei ${ }^{2}$, Timothy Hanlon ${ }^{3}$, David Mourer ${ }^{2}$ \\ ${ }^{1}$ GE Aviation; One Neumann Way, Cincinnati, OH, 45215, USA \\ ${ }^{2}$ GE Aviation; 1000 Western Avenue, Lynn, MA, 01910, USA \\ ${ }^{3}$ GE Global Research; One Research Circle, Niskayuna, NY, 12309, USA
}

Keywords: Alloy Development, Powder Metallurgy, superalloy, chemistry, disk alloy design, phase stability

\begin{abstract}
GE Aviation under the US Air Force Hybrid Disk Contract (FA8650-10-C-5225) investigated a powder nickel alloy design space in search of an alloy composition to increase the state of the art temperature capability for rotating disk applications to $1450{ }^{\circ} \mathrm{F}$ $\left(788{ }^{\circ} \mathrm{C}\right)$. The eleven alloy Design of Experiments (DOE) explored the relationship between chemistry and mechanical properties (creep, tensile, ductility, dwell LCF, cyclic fatigue crack growth \& static fatigue crack growth) as well as identified key attributes around gamma prime precipitation temperatures, phase stability and long term exposures and stability of gamma prime. Regression analysis of the data obtained indicates that increasing $\mathrm{W}$ and decreasing $\mathrm{Cr}$ and $\mathrm{Ti}$ are desirable for improved high temperature strength and creep capability.
\end{abstract}

\section{Introduction}

One of the key technologies limiting the increase in operating pressure ratios required for improved specific fuel consumption and thrust of aircraft engines is the capability of the core materials in the engine. Specifically, the nickel base superalloys utilized in the last stages of the high pressure compressor and the high pressure turbine. The alloying directions required for the improvement in durability and strength are known as a result of the extensive work done to advance both blade and disk alloys. [14] The problem with directly adapting this technology is the added complication of grain boundaries which are required to improve LCF capability (fine grain size) and the extreme size of these parts which require the component survive the high temperatures and stresses imparted during forging and heat treatment.

As part of the Air Force Hybrid Disk program, GE Aviation undertook the task of developing a series of alloys which were manufactured in subscale through representative processing methods to enable an evaluation of competing ideas on how to modify the chemistry to both improve creep and strength while maintaining other desirable properties. The program resulted in data that has led to future alloying directions and improvements to advanced disk alloys for use at temperatures up to $815^{\circ} \mathrm{C}$.

\section{Experimental Setup: Material Processing}

The eleven (11) alloy design of-experiment series, referred to as ME5XX, looked at the alloying effects of $\mathrm{Cr}, \mathrm{Nb}$, Ta, Co, Ti, Mo and $\mathrm{W}$ as seen in Figure 1. The center point of the DOE series, designated as alloy ME501, was an experimental alloy developed by GE Aviation prior to the Air Force Hybrid Disk program.

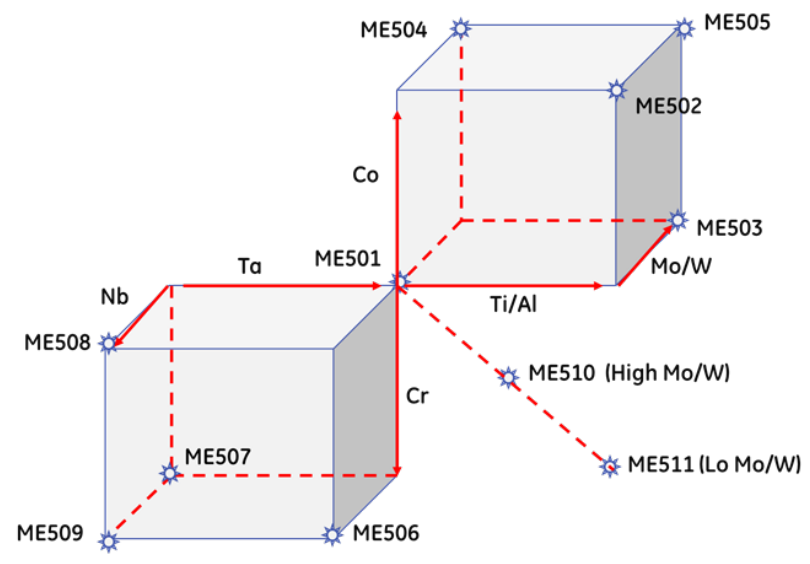

Figure 1: Two 3 level 3 factor partial factorial layout with ME501 linking them with ME510 \& ME511 on stand-alone vectors

The alloys defined in Table I were manufactured by powder metallurgy processing by Wyman Gordon Princeton Kentucky. Alloy chemistry was determined for primary matrix elements via $\mathrm{X}$-ray fluorescence, while oxygen, nitrogen, sulfur and carbon via inert gas fusion measurement. Boron levels were determined by inductively coupled plasma/optical emissions spectroscopy (ICPOES).

Table I: Requested chemistries for ME5XX DOE (weight percent)

\begin{tabular}{|l|c|c|c|c|c|c|c|c|c|c|c|c|}
\hline Name & Al & B & C & Co & Cr & Hf & Mo & Nb & Ta & Ti & W & Zr \\
\hline ME501 & 3.0 & 0.03 & 0.05 & 18 & 12 & 0.4 & 2.9 & 1.5 & 4.8 & 3.0 & 3.0 & 0.05 \\
\hline ME502 & 3.0 & 0.03 & 0.05 & 20 & 12 & 0.4 & 2.9 & 1.5 & 4.8 & 3.6 & 3.0 & 0.05 \\
\hline ME503 & 3.0 & 0.03 & 0.05 & 18 & 12 & 0.4 & 4.4 & 1.5 & 4.8 & 3.6 & 1.5 & 0.05 \\
\hline ME504 & 3.0 & 0.03 & 0.05 & 20 & 12 & 0.4 & 4.4 & 1.5 & 4.8 & 3.0 & 1.5 & 0.05 \\
\hline ME505 & 3.0 & 0.03 & 0.05 & 20 & 12 & 0.4 & 4.4 & 1.5 & 4.8 & 3.6 & 1.5 & 0.05 \\
\hline & \multicolumn{1}{|c|}{} & & & & & & & & & & \\
\hline ME506 & 3.0 & 0.03 & 0.05 & 18 & 13 & 0.4 & 2.9 & 2.0 & 4.8 & 3.0 & 3.0 & 0.05 \\
\hline ME507 & 3.0 & 0.03 & 0.05 & 18 & 13 & 0.4 & 2.9 & 1.5 & 4.0 & 3.0 & 3.0 & 0.05 \\
\hline ME508 & 3.0 & 0.03 & 0.05 & 18 & 12 & 0.4 & 2.9 & 2.0 & 4.0 & 3.0 & 3.0 & 0.05 \\
\hline ME509 & 3.0 & 0.03 & 0.05 & 18 & 13 & 0.4 & 2.9 & 2.0 & 4.0 & 3.0 & 3.0 & 0.05 \\
\hline & & & & & & & & & & & & \\
\hline ME510 & 3.0 & 0.03 & 0.05 & 20 & 13 & 0.4 & 4.4 & 2.0 & 4.0 & 3.6 & 1.5 & 0.05 \\
\hline ME511 & 3.0 & 0.03 & 0.05 & 20 & 13 & 0.4 & 2.9 & 2.0 & 4.0 & 3.6 & 3.0 & 0.05 \\
\hline
\end{tabular}

The ME5XX alloy chemistries were screened to -270 mesh fraction (nominal 53 micron screen opening) and canned under vacuum. Hot compaction and extrusions were used for alloy consolidation. This processing was performed by Wyman Gordon Houston Texas. All alloys were processed to the same hot compaction and extrusion parameters. After extrusion, the alloys were cropped to remove tail and nose material. (See Figure 2.) 


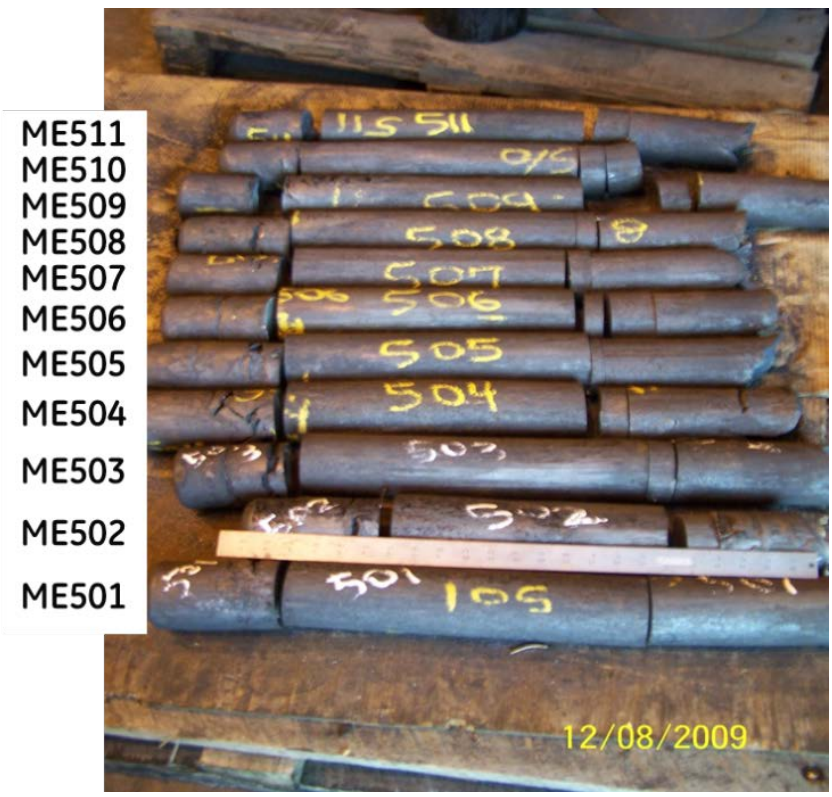

Figure 2: Photograph of the ME5XX extrusions $\sim 7.6 \mathrm{~cm}$ diameter (yard stick seen in picture)

The ME5XX alloys were evaluated as a forged product with mults isoforged to small pancakes (12.5 cm dia x $3.75 \mathrm{~cm}$ thick). Based on prior experience and ME5XX alloy TMP behavior, isoforged conditions at $1052{ }^{\circ} \mathrm{C}$ were used to target a nominal ASTM 6-8 (46-22 $\mu \mathrm{m}$ ) structure. Blanks were extracted from all the pancakes and were heat treated in a controlled vacuum environment using the fixture seen in Figure 3 to maintain a 111 ${ }^{\circ} \mathrm{C} /$ min cooling rate. All alloys were solutioned $\left(1191{ }^{\circ} \mathrm{C} / 1 \mathrm{hr}\right)$, stabilized $\left(843^{\circ} \mathrm{C} / 2 \mathrm{hr}\right)$ and aged $\left(760^{\circ} \mathrm{C} / 8 \mathrm{hrs}\right)$ to establish the baseline condition. After heat treatment the blanks were machined into test specimens for evaluation.

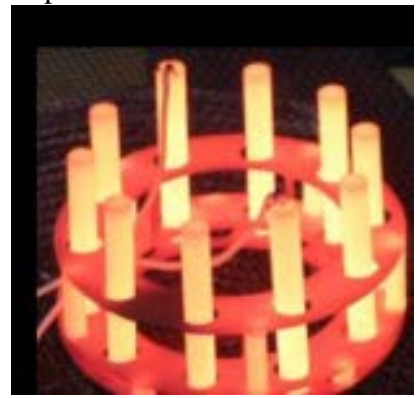

Figure 3: Heat treatment fixture used to minimize variation in the cooling rate from solution

\section{Mechanical Properties}

A standard set of properties were evaluated including tensile, creep, eLCF, dwell LCF and fatigue crack growth. Table II highlights the results found from mechanical property testing. The "+” shows that more of this element helps the property while the "-“ shows that more of this element hurts the property. This paper will explore in more depth the tensile and creep results.
Table II: Overview of elemental effects on properties

\begin{tabular}{|c|c|c|c|c|c|c|c|c|}
\hline \multirow{3}{*}{$\begin{array}{c}\text { ME5XX } \\
\text { DOE } \\
\text { Range }\end{array}$} & AL & Co & $\mathrm{Cr}$ & Mo & $\mathrm{Nb}$ & Ta & $\mathrm{Ti}$ & W \\
\hline & \multirow{2}{*}{3.0} & 20.0 & 13.0 & 4.4 & 2.0 & 4.8 & 3.6 & 3.0 \\
\hline & & 18.0 & 12.0 & 2.9 & 1.5 & 4.0 & 3.0 & 1.5 \\
\hline Tensile & & & & & + & + & ++ & + \\
\hline Ductility & & & + & & - & & & \\
\hline Creep & & & - & & & & -- & ++ \\
\hline
\end{tabular}

$\underline{\text { Tensile }}$

Smooth tensile specimens $0.635 \mathrm{~cm}$ diameter were manufactured and tested to ASTM E21 at $427^{\circ} \mathrm{C}, 650{ }^{\circ} \mathrm{C}, 760^{\circ} \mathrm{C}$ and $815^{\circ} \mathrm{C}$ as well as notched bars with an elastic stress concentration factor (Kt) of 3.5 tested at $650{ }^{\circ} \mathrm{C}$ and $760{ }^{\circ} \mathrm{C}$. The center point ME501 had the following yield strengths, ultimate tensile strengths and percent elongations as well as notched strengths.

Table III: Tensile capability of ME501 (MPa)

\begin{tabular}{|c|c|c|c|c|}
\hline Property & $\mathbf{4 2 7}^{\mathbf{}} \mathbf{C}$ & $\mathbf{6 5 0}^{\mathbf{}} \mathbf{C}$ & $\mathbf{7 6 0}^{\mathbf{}} \mathbf{C}$ & $\mathbf{8 1 5}^{\circ} \mathbf{C}$ \\
\hline YS & 1131 & 1096 & 1041 & 903 \\
\hline UTS & 1606 & 1496 & 1186 & 993 \\
\hline \%EL & 16 & 13 & 10 & 14 \\
\hline $\begin{array}{c}\text { Notched } \\
\text { UTS }\end{array}$ & & 1786 & 1793 & \\
\hline
\end{tabular}

The chemistry DOE showed a 70 MPa range around ME501 on yield strength and a $90 \mathrm{MPa}$ range on ultimate tensile strength as seen in Figure 4 \& Figure 5, respectively. Percent elongation and notched UTS are shown in Figure 6 and 7 respectively.

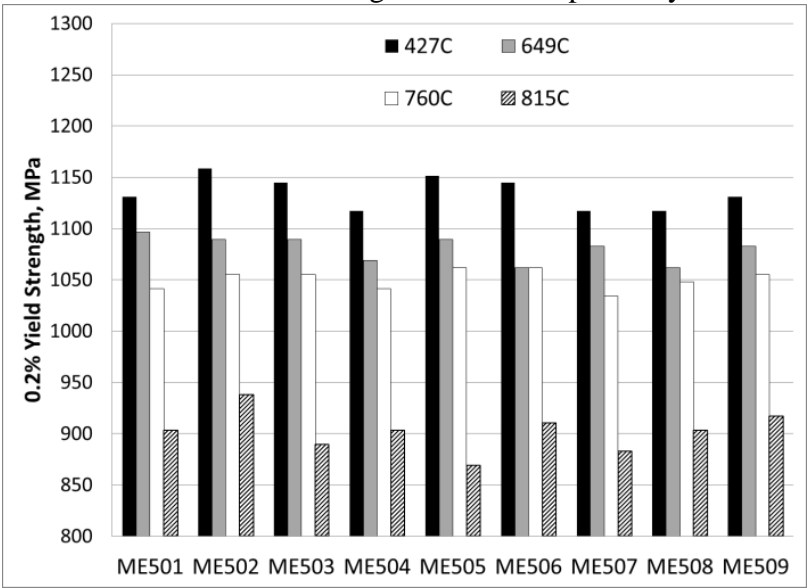

Figure 4: $0.2 \%$ Yield strength response in ME5XX DOE 


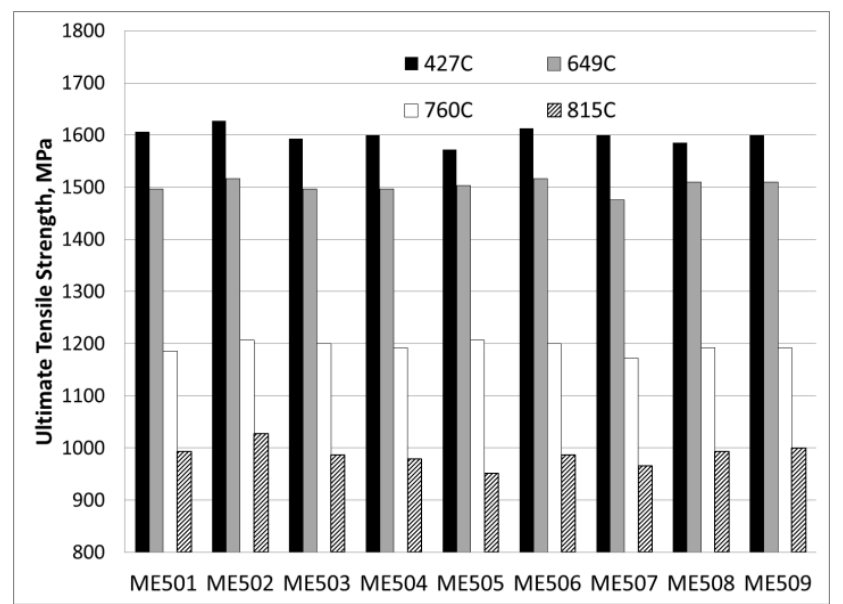

Figure 5: Ultimate tensile response in ME5XX DOE

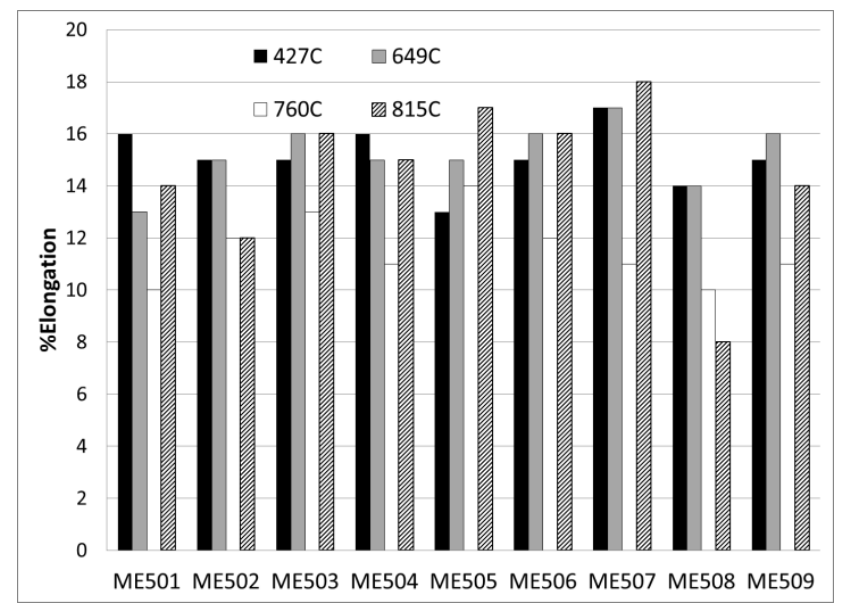

Figure 6: \%Elongation response in ME5XX DOE

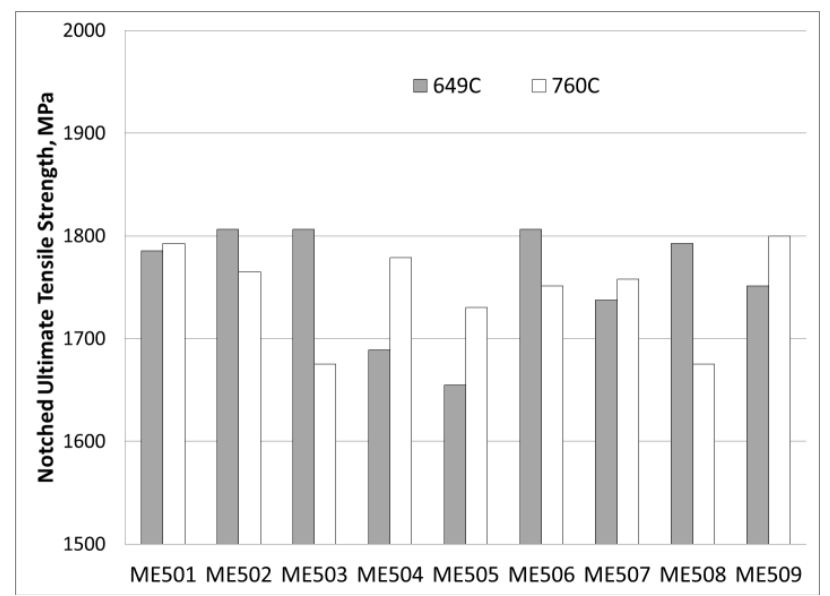

Figure 7: Notched UTS response in ME5XX DOE

\section{Creep}

Smooth creep specimens $0.635 \mathrm{~cm}$ diameter were manufactured and tested to ASTM 6 at $704^{\circ} \mathrm{C} @ 690 \mathrm{MPa}, 760^{\circ} \mathrm{C} @ 500 \mathrm{MPa}$ and $815^{\circ} \mathrm{C} @ 345 \mathrm{MPa}$. Each test was run out to failure. Results for ME501 are shown in Table IV. Individual alloy variations are shown in Figures 8 - 10.
Table IV: Hrs to $0.2 \%$ Creep and rupture capability of ME501

\begin{tabular}{|c|c|c|c|}
\hline & $\begin{array}{c}704{ }^{\circ} \mathrm{C} @ \\
690 \mathrm{MPa}\end{array}$ & $\begin{array}{c}760{ }^{\circ} \mathrm{C} @ \\
500 \mathrm{MPa}\end{array}$ & $\begin{array}{c}815^{\circ} \mathrm{C} @ \\
345 \mathrm{MPa}\end{array}$ \\
\hline $\begin{array}{c}0.2 \% \\
\text { Creep }\end{array}$ & $567 \mathrm{hrs}$ & $217 \mathrm{hrs}$ & $69.5 \mathrm{hrs}$ \\
\hline Rupture & $4359 \mathrm{hrs}$ & $1739 \mathrm{hrs}$ & $532 \mathrm{hrs}$ \\
\hline $\begin{array}{c}\text { Rupture } \\
\text { Ductility }\end{array}$ & $19 \%$ & $18 \%$ & $14 \%$ \\
\hline
\end{tabular}

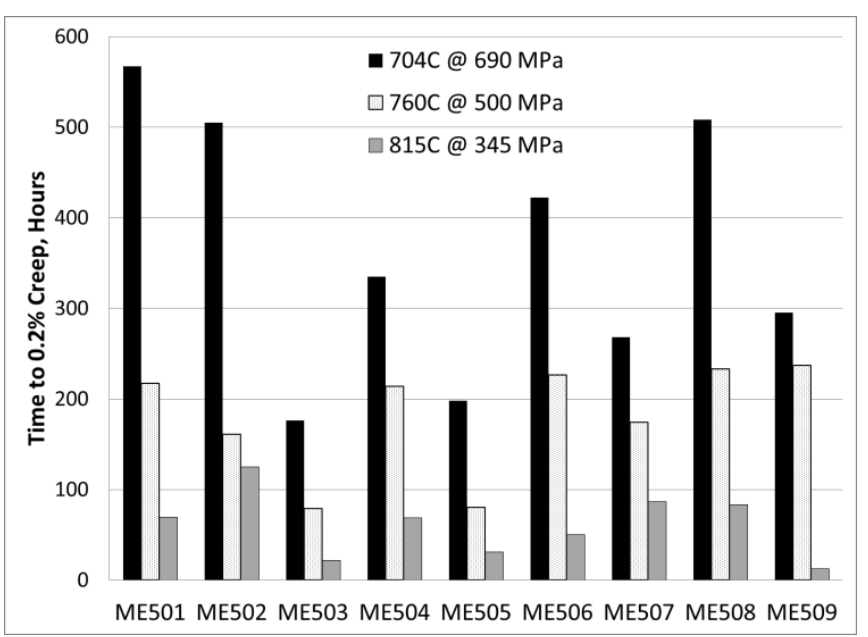

Figure 8: Time to $0.2 \%$ creep strain response in ME5XX DOE

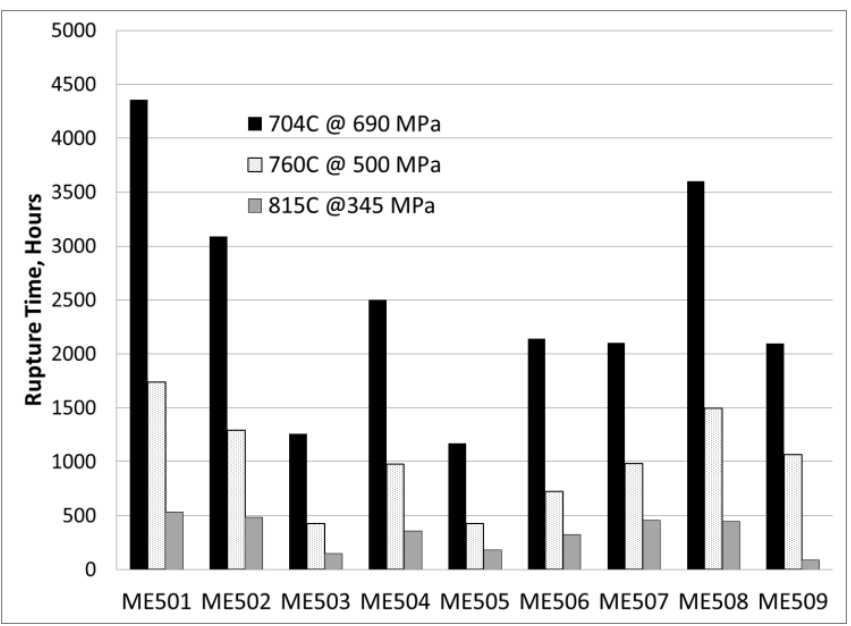

Figure 9: Time to creep rupture response in ME5XX DOE 


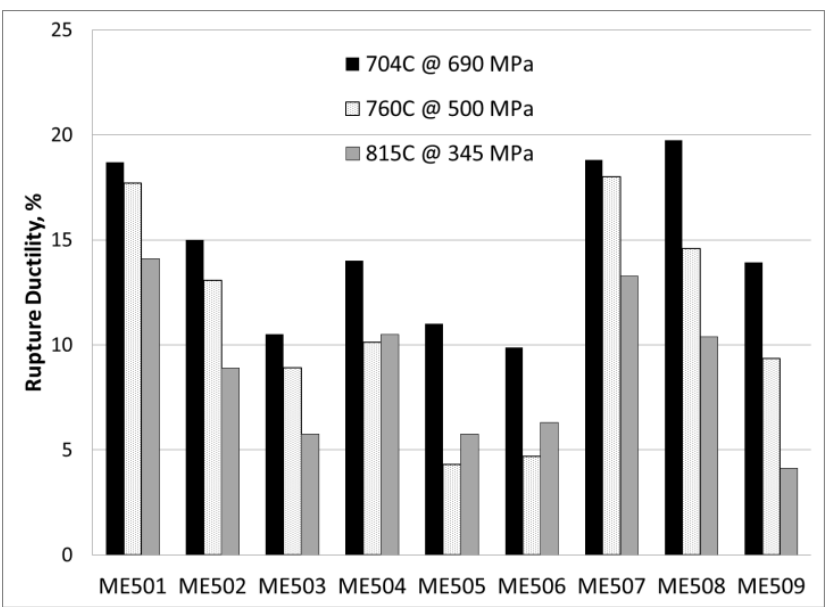

Figure 10: Rupture ductility response in ME5XX DOE

For the purposes of the analysis, the time to $0.2 \%$ creep strain data was log-averaged together and the deviation from that log-average was used to regress and investigate trends. (See Figure 11.)

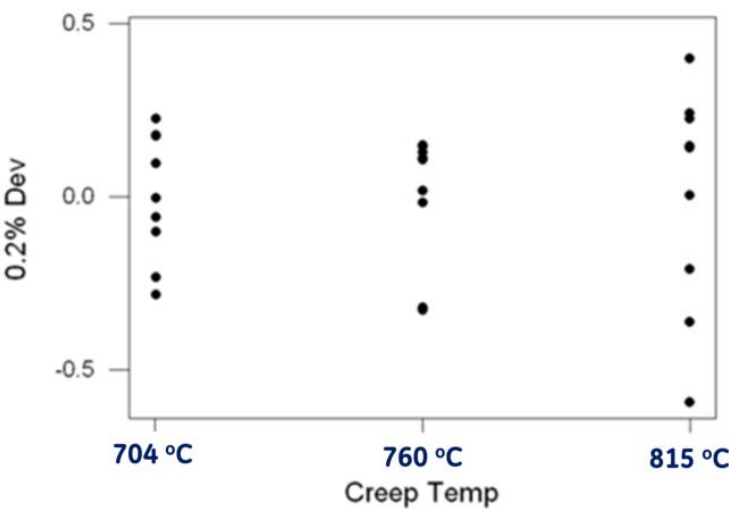

Figure 11: Deviation from average in log space for $0.2 \%$ creep.

Significantly more scatter was recorded at $815^{\circ} \mathrm{C}$ and therefore was removed from the regression.

Using Minitab linear regression, the best fit equation is:

$$
0.2 \% \mathrm{DEV}=2.59-0.149 \mathrm{Cr}-0.981 \mathrm{Ti} / \mathrm{Al}+0.367 \mathrm{~W} / \mathrm{Mo}
$$

Analysis showed strong chemistry effect at $704^{\circ} \mathrm{C} \& 760^{\circ} \mathrm{C}$ with weak trends at $815{ }^{\circ} \mathrm{C}$. Increasing $\mathrm{W}$ and decreasing $\mathrm{Cr}$ are the best alloying directions to improve creep. Increased scatter at 815 ${ }^{\circ} \mathrm{C}$ may be due to shift in damage mechanism that is more dominated by grain size. Main effect plot from analysis are shown in Figure 12.

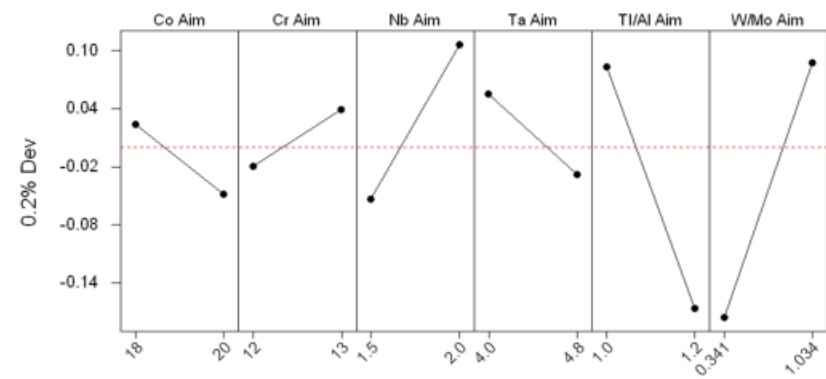

Figure 12: Main effect plots for $0.2 \%$ creep deviations.

\section{Single Sensor Differential Thermal Analysis (SS-DTA)}

Single Sensor Differential Thermal Analysis (SS-DTA) was used to determine the gamma-prime solvii and non-equilibrium precipitation ranges for the ME5XX alloys. The alloy thermograms were processed to derive the onset of gamma prime precipitation. The SS DTA technique was developed to detect phase transformations during non-equilibrium conditions, such as those seen in welding processes [5,6]. The work for this program was performed at The Ohio State University Materials Engineering Welding Group.

Essentially, SS-DTA is a method to identify phase transformation and any order /disorder structure change in alloys under heat treatment or metal processing conditions. From measuring temperature with signal processing, a thermal history of the specimen being processed or evaluated is recorded for the regimes that undergo phase transformations. This method differs from conventional DTA, which relies on the acquisition of actual reference temperature data to compare sensed specimen temperature. The conventional DTA method requires extensive calibration for thermal and kinetic effects (cooling rate). SS-DTA utilizes numerical modeling or physics based fitting algorithms for thermal history measured by a single sensor.

The phase transformation temperatures determined by SS-DTA software are presented in Figure 13 for alloy ME501 with cooling rate range from 22 to $240{ }^{\circ} \mathrm{C} / \mathrm{min}$. The plots show the orderdisorder phase transformation (gamma prime precipitation) can be clearly identified by the arrest temperature.

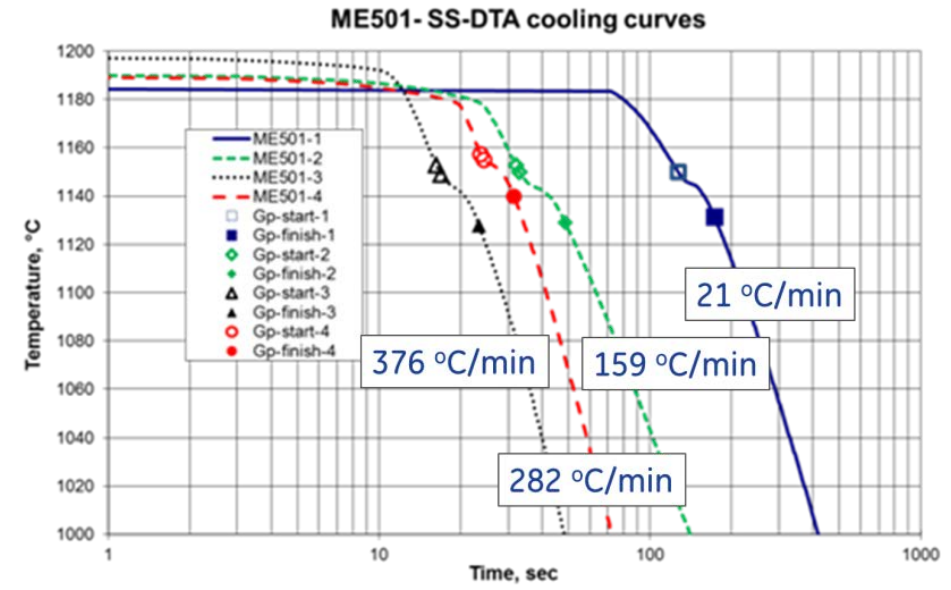

Figure 13: Alloy ME501 gamma prime phase transformation temperature plot vs. cooling rate 
The large thermal effect of the initial secondary gamma-prime precipitation event can easily be identified by SS DTA. Although seen in prior experiments on other powder alloys, the subsequent tertiary gamma prime precipitation event could not reliably be identified in the ME5XX specimens. The inability to clearly detect the tertiary precipitation burst is believed to be due to low signal to noise ratio from the sample size used and the very low magnitude of latent heat released.

The gamma prime precipitation starting temperatures are found to be relatively insensitive to the cooling rate range of interest for disk heat treat cooling rate range $\left(23-77^{\circ} \mathrm{C} / \mathrm{min}\right)$. However, the onset of gamma prime precipitation exhibits a sizable drop for cooling rates above $278^{\circ} \mathrm{C} / \mathrm{min}$. The micrographs of gamma prime shown in Figure 14 indicate that the nucleation density, and thus the size and size distribution of precipitates, are strong functions of cooling rates. Morphology differences also arise, as the large misfit between the precipitates and the gamma matrix causes larger particles in the slow cooled structures to take on a lobed appearance. This information will be valuable for understanding gamma prime kinetic heat treat effects.

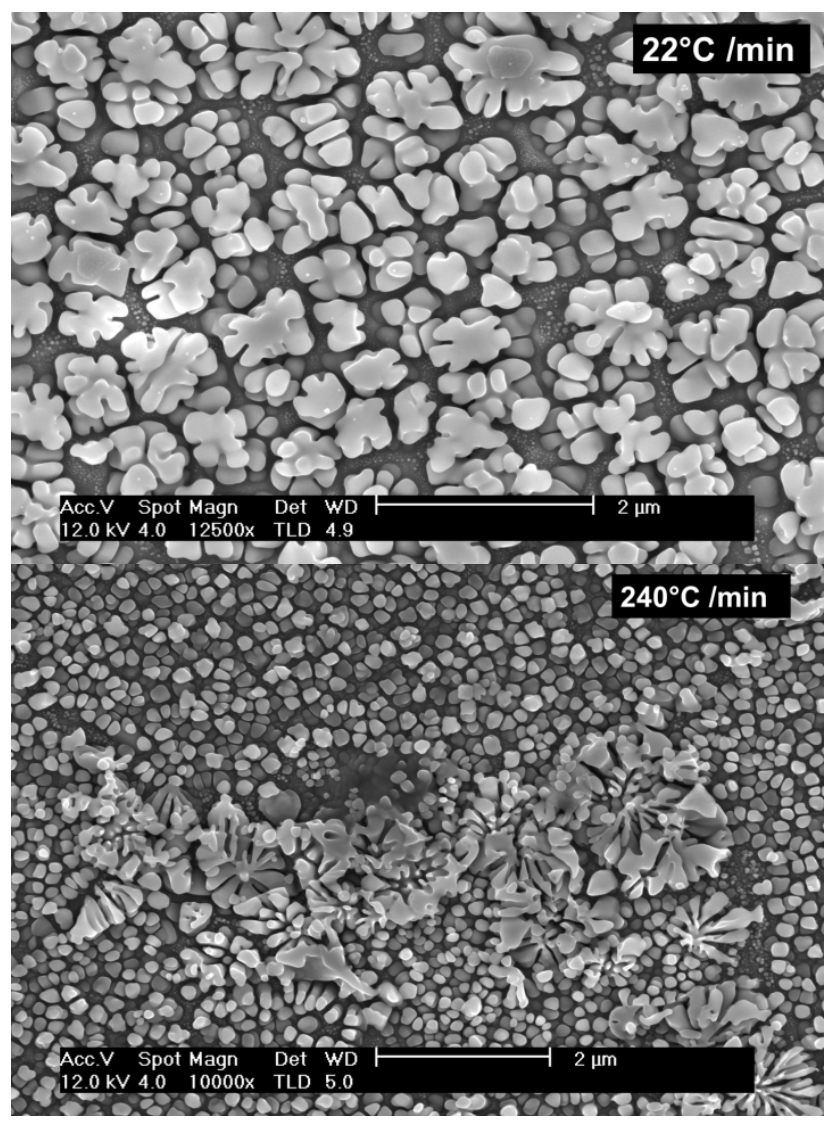

Figure 14: ME501 secondary gamma prime SEM micrographs at $22{ }^{\circ} \mathrm{C} / \mathrm{min}$ and $240{ }^{\circ} \mathrm{C} / \mathrm{min}$ cooling rates

\section{Long Term Phase Stability And Gamma Prime Coarsening}

Alloy in-service stability is a key characteristic so in addition standard heat treatment cycle all alloys were given a $760{ }^{\circ} \mathrm{C} / 1000$ hr furnace soak to simulate service exposure.
The relative propensity of the ME5XX alloys to precipitate TCP phases, such as $\eta$ and $\sigma$, was predicted using the CALPHAD approach. The eleven alloys were rank-ordered based on these predictions from 1 to 11 , with a lower value indicating a higher likelihood of TCP phase formation (Table V), All alloys were then given a qualitative rating based on the visible amount of acicular phases observed experimentally. A scale of $0-2$ was used, with 0 indicating no TCP precipitation, 1 indicating an intermediate amount of TCP content, and 2 indicating noticeable/significant TCP precipitation. Only one alloy, ME510, showed clear phase instabilities. Alloys ME511 and ME503 showed lower instability levels and were considered borderline. Such chemistries were deemed critical in defining the boundaries of stability in this chemistry range. Additionally, the general agreement with the phase predictions reflects the utility of digitally screening such alloys with thermodynamic modeling tools.

A confirmatory examination of ME510 via Electron Probe Micro Analysis (EPMA) was performed to identify the acicular phase content observed. The Wavelength Dispersive $\underline{\text { Spectrometry }}$ (WDS) chemistry analysis in Figure 15 indicates that the needles observed are $\mathrm{Ti} / \mathrm{Nb} / \mathrm{Ta}$ rich and $\mathrm{W} / \mathrm{Mo} / \mathrm{Cr}$ depleted, characteristic of $\eta$.

The fact that only 3 alloys showed any signs of instability or TCP phase formation is considered positive in light of the aggressive alloying levels chosen.

Table V: Summaries of $760^{\circ} \mathrm{C}$ exposure alloy stability results

\begin{tabular}{|c|c|c|c|}
\hline Alloy & $\begin{array}{c}\text { Acicular Phase } \\
\text { Rating (0-3) }\end{array}$ & $\begin{array}{c}\text { Predicted Eta } \\
\text { Formation Rank }\end{array}$ & $\begin{array}{c}\text { Predicted Sigma } \\
\text { Formation Rank }\end{array}$ \\
\hline 501 & 0 & 8 & 10 \\
\hline 502 & 0 & 3 & 8 \\
\hline 503 & 1 & 2 & 5 \\
\hline 504 & 0 & 10 & 9 \\
\hline 505 & 0 & 4 & 4 \\
\hline 506 & 0 & 6 & 3 \\
\hline 507 & 0 & 11 & 7 \\
\hline 508 & 0 & 7 & 11 \\
\hline 509 & 0 & 9 & 6 \\
\hline 510 & 2 & 1 & 1 \\
\hline 511 & 1.5 & 5 & 2 \\
\hline
\end{tabular}



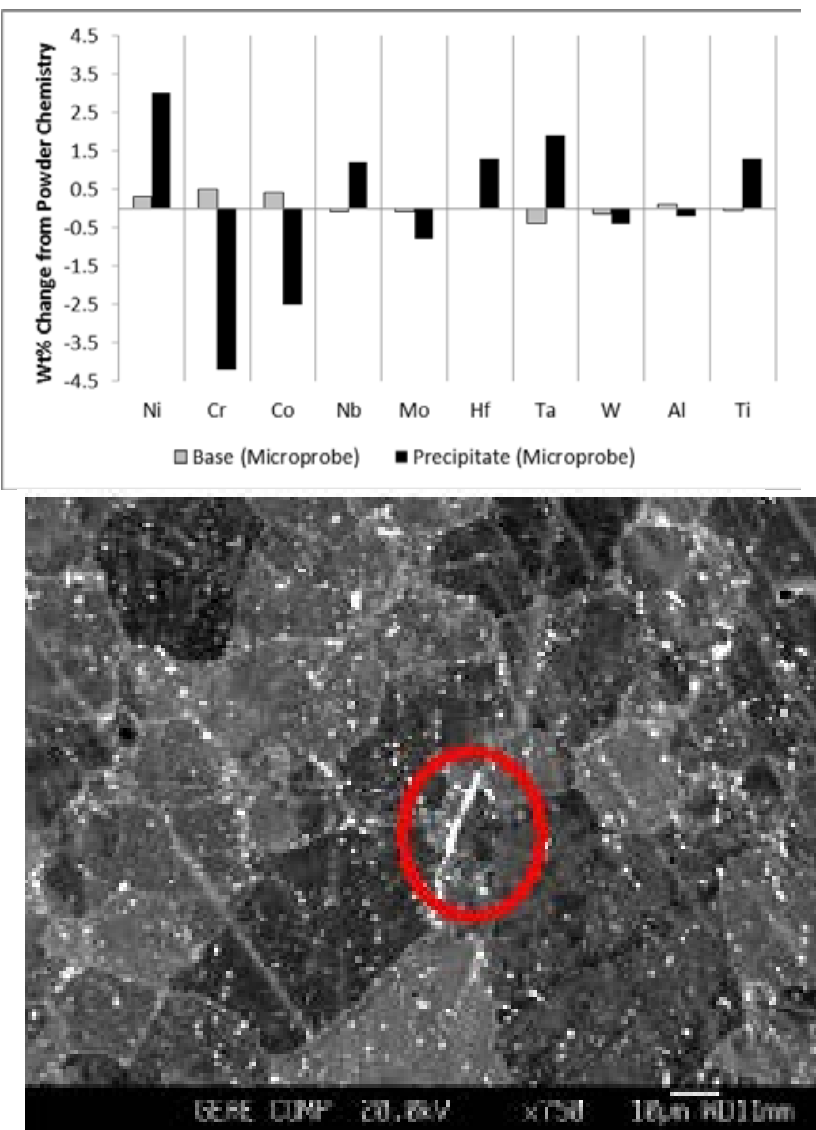

Figure 15: Alloy ME510. Acicular phase analysis.

Five ME5XX alloys were also down-selected for gamma prime coarsening measurements as a function of thermal exposure at $704^{\circ} \mathrm{C}, 760^{\circ} \mathrm{C}$, and $815^{\circ} \mathrm{C}$, for up to $3000 \mathrm{hr}$. Figure 16 indicates the exceptional grain size stability in ME501, a trait common among each of the ME5XX alloys under the exposure conditions evaluated.

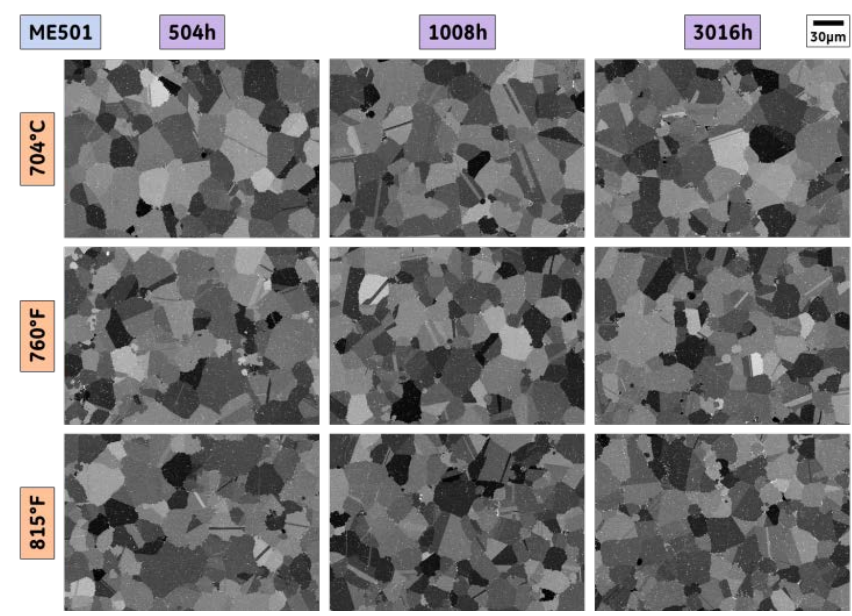

Figure 16: Low magnification backscatter SEM images of ME501 as a function of exposure time and temperature.
The calculated gamma/gamma prime misfit for ME5XX alloys show a wide spectrum ranging from positive $(0.040 \%)$ to negative misfit $(-0.032 \%)$, which should indicate variation in coarsening and creep behavior. The sign and magnitude of the misfit between the gamma and the ordered gamma prime phase also determines the morphology of the gamma prime precipitates and their orientation under applied loading. Based on their predicted variation in gamma/gamma prime misfit, alloys ME501, ME504, ME505, ME508 and ME510 were selected for evaluation of coarsening behavior.

Figure 17 shows the quantitative image analysis on tertiary and secondary gamma prime sizes performed after the thermal exposures. Minor tertiary gamma prime coarsening was observed out to $760{ }^{\circ} \mathrm{C} / 1000 \mathrm{hr}$, followed by a more significant coarsening between $1000 \mathrm{hr}$ and $3000 \mathrm{hr}$. The apparent shorter term stability may be a function of simultaneous continued precipitation of very fine aging gamma prime, and its subsequent coarsening. A slight increase in average secondary gamma prime size is measured at $760{ }^{\circ} \mathrm{C} / 1008 \mathrm{hr}$ in each alloy, but sizes remain relatively stable from that point forward, through $3016 \mathrm{hr}$.

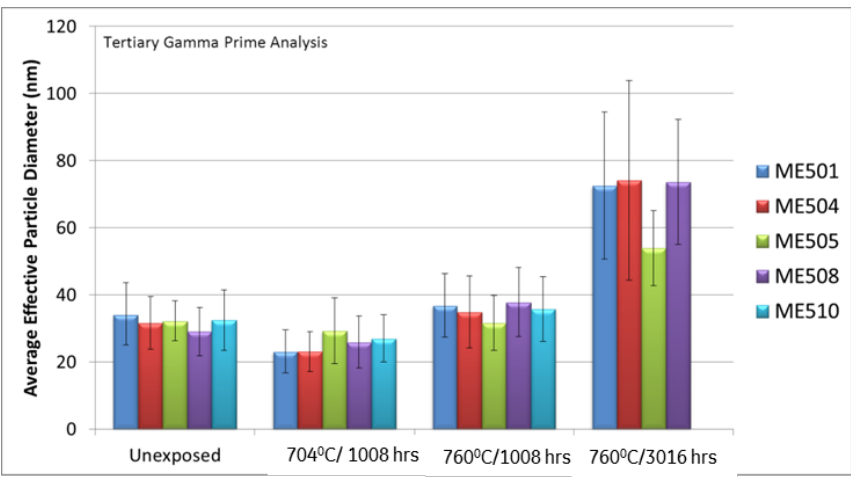

(a)

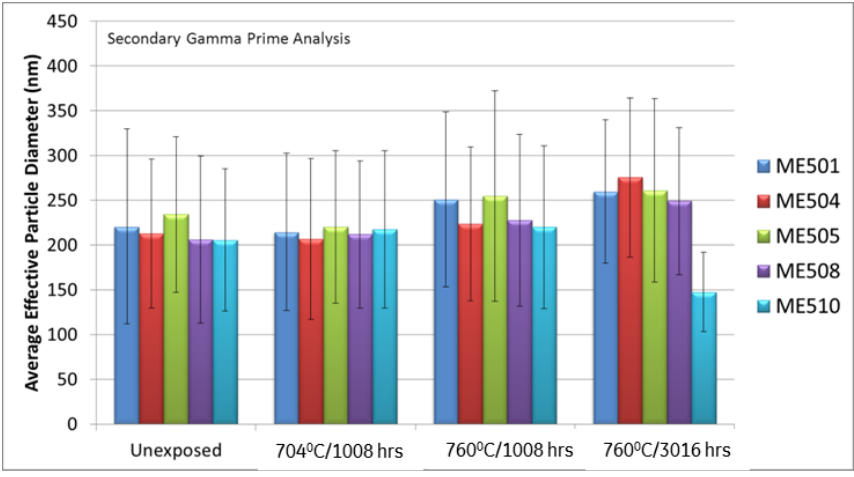

(b)

Figure 17: Quantitative image analysis of (a) tertiary and (b) secondary gamma prime particles.

Deep-gamma-etch analyses were also conducted on ME501 to reveal the three dimensional nature of gamma prime evolution as a function of exposure temperature and time (Figure 18 through Figure 20). At $704{ }^{\circ} \mathrm{C}$, Figure 18 indicates relative size- and morphology-stability of secondary, tertiary and fan gamma prime, out to 3016 hours. At $760{ }^{\circ} \mathrm{C}$, lobed secondary gamma prime shows a morphology shift (incomplete at $3016 \mathrm{hrs)}$ toward cuboidal, tertiary gamma prime coarsening is evident, and fan gamma prime particles remain relatively stable in size and morphology. Exposures at $760{ }^{\circ} \mathrm{C}$ (Figure 20) indicate a more 
complete shift from lobed to cuboidal secondary gamma prime, a near complete dissolution of tertiary gamma prime, and continued stability of fan gamma prime. Gamma prime size and morphology stability are critical attributes relative to long term property stability. As an example, tertiary gamma prime size and spacing drives the interaction between gamma channel width and dislocation mobility, which has been shown to influence high temperature creep behavior. [7]. The complete dissolution of tertiary gamma prime particles apparent at all $815{ }^{\circ} \mathrm{C}$ exposure intervals therefore indicates a temperature limit of the ME5XX alloys closer to $760{ }^{\circ} \mathrm{C}$.
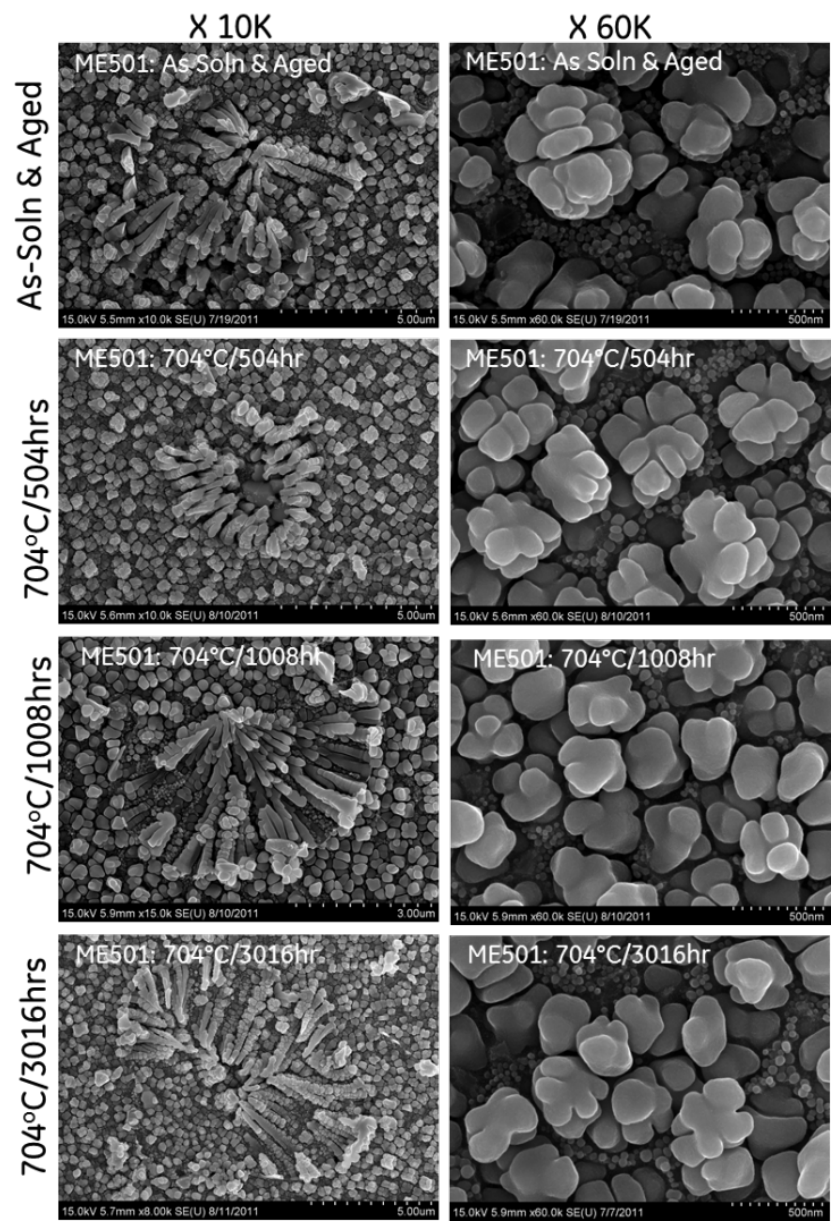

Figure 18: Deep gamma etch revealing gamma prime and fan gamma prime evolution at $704^{\circ} \mathrm{C}$, as a function of exposure time
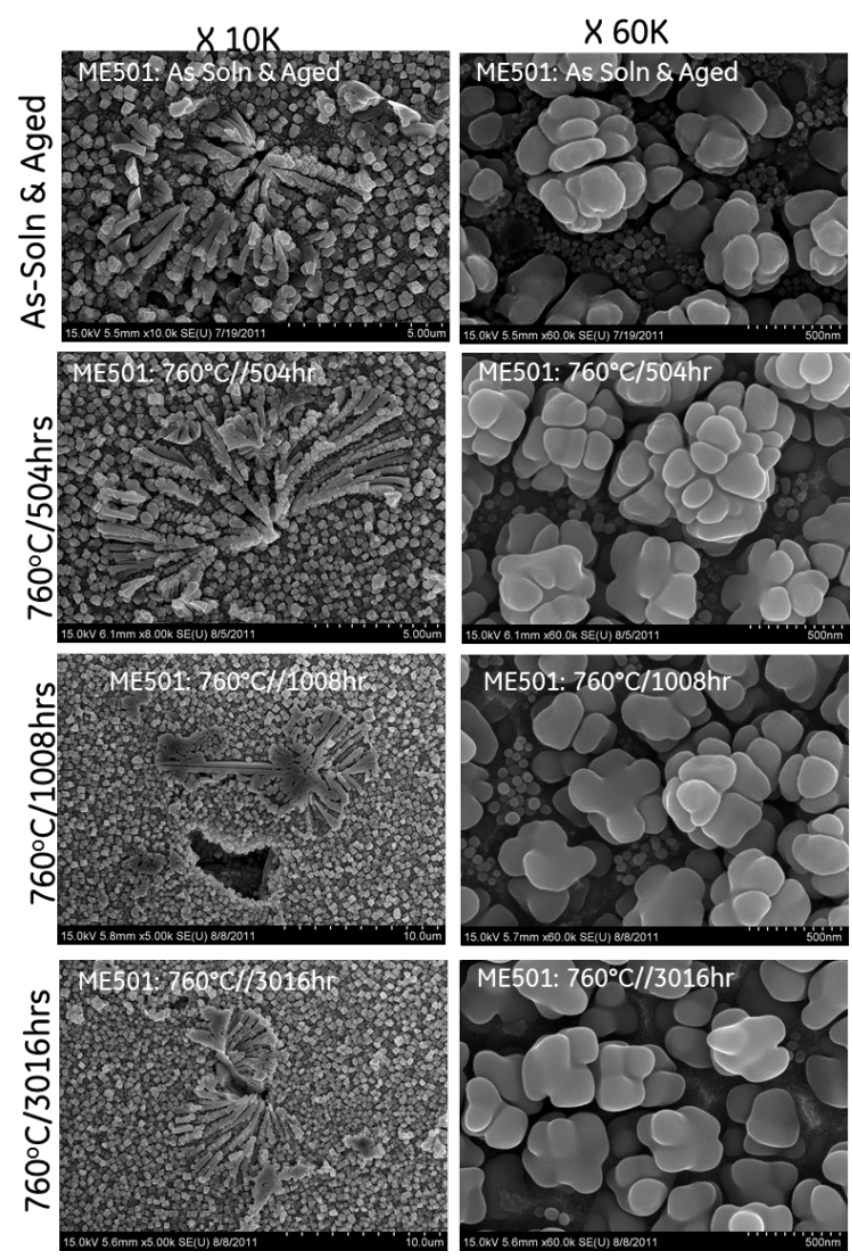

Figure 19: Deep gamma etch revealing gamma prime and fan gamma prime evolution at $760^{\circ} \mathrm{C}$, as a function of exposure time 


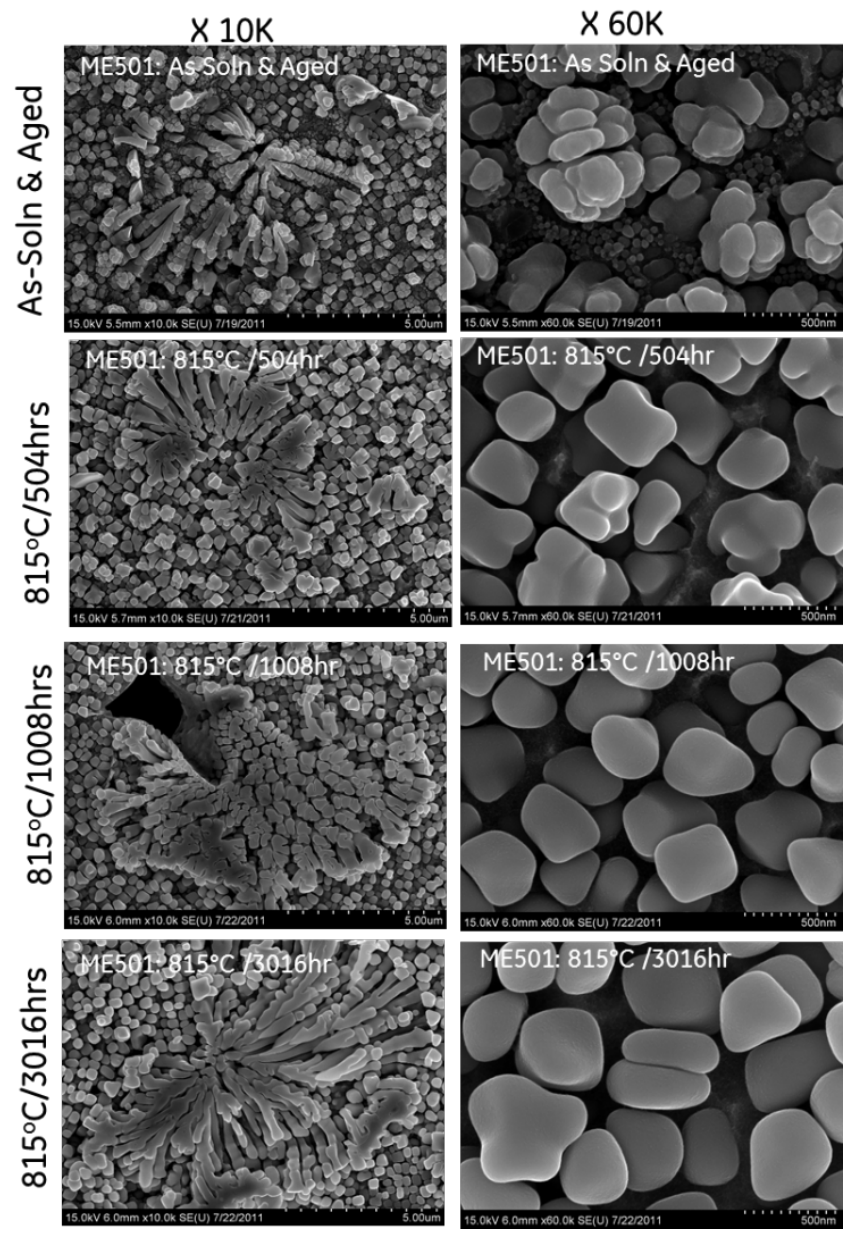

Figure 20: Deep gamma etch revealing gamma prime and fan gamma prime evolution at $815^{\circ} \mathrm{C}$, as a function of exposure time

\section{Conclusions}

A DOE was executed with the goal of improving high temperature capability of advanced nickel disk alloys. This DOE was developed to explore alloying directions that evolved as a result of many programs in the past 25 years centered on extending the high strength capability of critical powder metallurgy disks.

The DOE investigated the effect of both gamma prime forming elements such as $\mathrm{Ta}, \mathrm{Nb}, \mathrm{Ti}$ and $\mathrm{Al}$ and gamma strengthening elements such as W and Mo. Co was investigated due to its effect on gamma prime solvus. Cr was investigated due to its influence on the formation of undesirable TCP phases. Several conclusions were developed as well as many insightful observations and evaluation techniques such as SS DTA to evaluate gamma prime formation temperatures.

The powders of each chemistry were forged into subscale pancakes and these were blanked and heat treated as blanks to allow precise control of thermal cycle and cooling rates. All alloys were tested for tensile strength, creep strength, fatigue capability and damage tolerance.

The key findings for high temperature strength are: o Titanium is a desirable element for tensile strength, but debits creep capability.

o Tungsten is broadly useful in improving both tensile and creep strength of the alloys

o Results for chromium, cobalt, tantalum and niobium are mixed.

Gamma prime solvus determination was conducted via single sensor differential thermal analysis and was observed to correlate with other methods and was very repeatable.

Stability of the structure was evaluated and three alloys ME503, ME510 and ME511 exhibited increased amounts of TCP phase formation which can debit key properties.

Desirable capability for advanced gas turbine alloys was observed for alloys with increased tungsten due to improved creep resistance. This is balanced by control of $\mathrm{Cr}$, Ta and $\mathrm{Ti}$ levels to minimize tendency to form eta phase which prior studies have observed to be bad for creep resistance.

Thermal exposure studies indicated that the size of the fine gamma prime particles was changing quickly at $760{ }^{\circ} \mathrm{C}$ and was quickly dissolved at exposures of $815{ }^{\circ} \mathrm{C}$. This data would suggest that these alloys will have creep strength issues above 760 ${ }^{\circ} \mathrm{C}$. Therefore resistance to creep strain accumulation is therefore reliant on gamma phase and secondary gamma prime precipitates.

Overall this study will lead to the development of improved stability alloys with higher creep, tensile and dwell characteristics.

\section{Acknowledgements}

The authors would like to acknowledge the significant ongoing support for PM disk alloy development provided by multiple government agencies over the past 25 year. Support from NASA via the EPM program, US Navy via the High Temperature Turbine Disk Material program, and the US Air Force via multiple programs. We would also like to specifically acknowledge the late Dallis Hardwick for her vision and direction in launching the Hybrid Disk program efforts as well as Michael Caton and Jay Tiley for their on-going support throughout the Hybrid Disk contract. All of this support has enabled development of multiple generations of subscale alloys and the data has allowed industry to advance capability via the cumulative learning of all of these programs.

\section{References:}

1. J. Gayda, T. P. Gabb, and R. V. Miner, "Fatigue Crack Propagation of Nickel Base Superalloys at $650{ }^{\circ} \mathrm{C}$ ” (NASA TM 87150, 1985)

2. J. J. Schirra et al., "Effect of Microstructure (and Heat Treatment) on the $649{ }^{\circ} \mathrm{C}$ Properties of Advanced PM Superalloy Disk Materials”, Superalloys 2004, Eds. K.A. Green et al (Warrendale, PA: The Minerals, Metals and Materials Society, 2004) 341-350

3. E.S. Huron et al., "Development of High Temperature Capability P/M Disk Superalloys” Superalloys 2008, Eds. R.C. Reed et al., (Warrendale, PA: The Minerals, Metals and Materials Society, 2008) 181-189 
4. E.S. Huron et. al., "The Influence of Grain Boundary Elements on Properties and Microstructures of P/M Nickel Base Superalloys", Superalloys 2004, Eds. K.A. Green et al (Warrendale, PA: The Minerals, Metals and Materials Society, 2004) pp 73-82

5.B. Alexandrov et al., "Non-equilbrium Phase Transformation Diagrams in Enginneering Alloys," Trends in Welding Research, vol. VIII, pp. 467-476, 2008.

6. B. Alexandrov et al., "Single Sensor Differntial THermal Analysis of Phase Transformation and Structural Changes during Welding and Postweld Heat Treatment," Welding in the World, vol. 51, pp. 48-59, 2007.

7. R. Oruganti et al., "A New Approach to Modeling of Creep in Superalloys”, Superalloys 2012, Eds. E.S. Huron et al (Warrendale, PA: The Minerals, Metals and Materials Society, 2012) 473-479. 